\title{
Dr. Jorge Dagnino Sepúlveda; Primer anestesiólogo Miembro Honorario de la Academia Chilena de Medicina
}

\author{
Jorge Dagnino Sepúlveda M.D \\ First anesthesiologist Honorary Member of \\ Medicine Academy
}

Ricardo Bustamante Bozzo1, Guillermo Lema Fuxman², Silvana Cavallieri , María Carolina Cabrera ${ }^{4}$

E I día 9 de diciembre de 2020 a las 11 horas, el Dr. Jorge Dagnino Sepúlveda, en una sesión solemne en forma virtual y en vivo a través de la página www.academiachilenademedicina.cl, fue recibido como Miembro Honorario de la Academia de Medicina. La ceremonia se había postergado varias veces por las circunstancias epidemiológicas y sanitarias que vive el país y finalmente se optó por hacerlo en línea para no seguir aplazando el acto.

La corporación había entregado la distinción el 6 de diciembre de 2019 en sesión extraordinaria. Al adoptar esta resolución, la Academia Chilena de Medicina tuvo en consideración su destacada trayectoria en la especialidad de Anestesiología, su importante contribución en la formación de especialistas en Anestesiología y Cirugía General en la Facultad de Medicina de la Pontificia Universidad Católica, su incidencia en la administración universitaria y su aporte en las líneas de investigación sobre la regulación de la presión arterial y la hipertensión en las distintas etapas de la anestesia.

La Academia de Medicina de Chile es una corporación pública, autónoma en su organización y funciones, integrada por médicos destacados por su contribución al progreso de la medicina, la educación médica y la salud pública en Chile, comprometidos en la defensa de los valores éticos y morales de la medicina y el respeto a su tradición, historia y figuras ejemplares. Forma parte del Instituto de Chile, juntamente con las Academias: Chilena de la Lengua, Chilena de la Historia, Chilena de Ciencias, Chilena de Ciencias Sociales, Políticas y Morales y Chilena de Bellas Artes. Es importante destacar que desde septiembre de 1964 en que se promulgó la ley que dio origen a la corporación, el Dr. Jorge Dagnino es el primer anestesiólogo en ingresar a la Academia en sus 56 años de existencia. De esta forma, su incorporación, además del merecido reconocimiento personal, representa un orgullo para la Anestesiología Chilena.

En la primera parte de la ceremonia el Dr. Rodolfo Armas Merino, presidente de la Academia Chilena de Medicina, dio la bienvenida y agradeció la presencia de diferentes autoridades. En la segunda parte, el Dr. Augusto León Ramírez hizo un discurso de recepción al nuevo integrante. Finalmente, el Dr. Jorge Dagnino presentó su trabajo de incorporación: "La Vida es Sueño".

Maestro de la Anestesiología, Anestesiólogo Hospital de Urgencia Asistencia Pública, Ex Editor Revista Chilena de Anestesia.

Profesor Titular de Anestesiología, Pontificia Universidad Católica de Chile, Ex Editor Revista Chilena de Anestesia.

3 Anestesiólogo Hospital de Niños Dr. Luis Calvo Mackenna y Clínica las Condes, Ex presidenta de la Sociedad de Anestesiología de Chile.

4 Profesor Auxiliar de Anestesiología, Universidad de Valparaíso Sede Hospital FACH, Editora Jefe Revista Chilena de Anestesia.

\section{ORCID}

0000-0002-6105-5780

Correspondencia:

María Carolina Cabrera Schulmeyer

maria.cabrera@uv.cl 


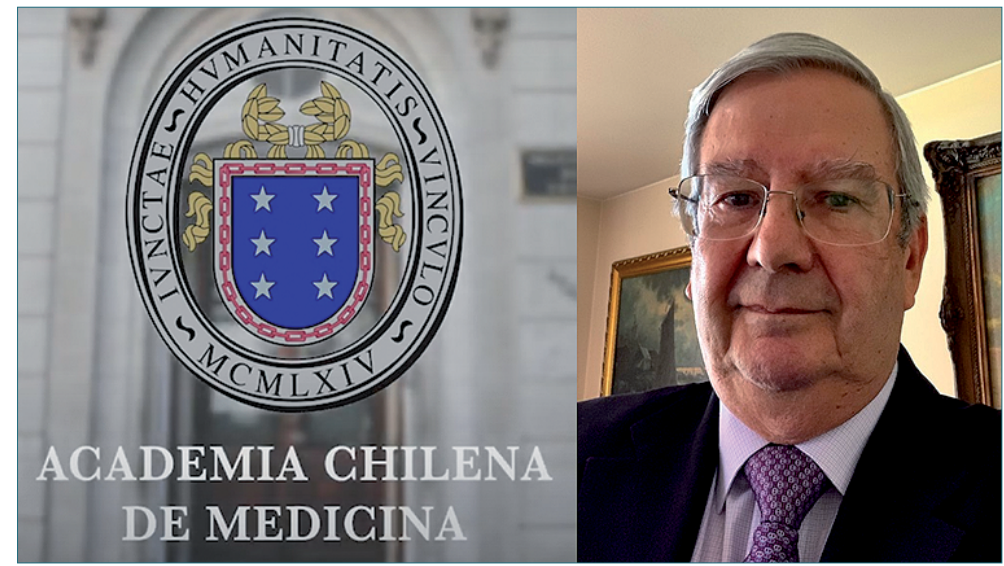

E Dr. Dagnino nació en Bogotá, siendo hijo del Agregado Comercial Chile en Colombia, Sr. Julio Dagnino Ruiz y de la Sra. Adriana Sepúlveda Prieto, Luego, el padre y la familia partieron a México con igual cargo y cumplidos seis años retornó a Chile. Sus estudios primarios y secundarios los hizo en The Grange School. Estudió medicina en la Universidad Católica entre los años 1965 y 1972. Es casado con Mónica Jiménez Varela y tiene cuatro hijos: Jorge, Sebastián, Alejandro y Cristián, y tres nietos, Lucía, Eleonora y José.

Después de ser médico general de zona en Curicó, el Dr. Dagnino volvió a la Universidad Católica con una beca de retorno a formarse en la especialidad de anestesiología. Terminada su formación hizo una estadía en Inglaterra entre 1982 y 1984 a través del British Council, siendo Research Felow y Senior Registrar en el Sir Humphry Davy Department of Anaesthetic, Bristol, bajo la dirección del Prof. Cedric Prys-Roberts y luego becado de la Wellcome Trust. Una vez de vuelta en Chile, se dedicó a la docencia de la especialidad, contribuyendo así al desarrollo y consolidación, juntamente con sus colegas y amigos José de la Fuente y Samuel Torregrosa, de lo que llegaría a ser el Departamento y posteriormente División de Anestesiología más importante del país, por el número de alumnos de postgrado, la calidad de la formación y la cantidad y calidad de la investigación clínica allí realizadas. La amistad y complementariedad de estos tres profesionales fue un factor importante para que en ese lugar se hayan formado más de 400 anestesiólogos hasta la fecha, actualmente distribuidos por todo el país, y para que la investigación clínica haya dado fruto a los artículos científicos nacionales e internacionales más numerosos y de calidad de nuestra especialidad.

Entre los intereses del Dr. Dagnino a lo largo de su carrera están la educación médica, tanto en su calidad como en su aspecto asistencial y la seguridad del paciente. Es así como formó parte de CONACEM (Comisión Nacional de Certificación de Especialidades Médicas) y de la JCAHO (Joint Commission on Accreditation of Healthcare Organizations). Fue director del proyecto MECESUP (Mejoramiento de la Calidad de la Educación Superior) para implementar la simulación de procedimientos médicos y el entrenamiento de los equipos de salud. También fue uno de los primeros anestesiólogos en interesarse en la informática y en la bioestadística, cuando el acceso a un computador era casi imposible y, cuando se aceptaba todo aquello que se publicaba, especialmente si era en otro idioma.

Entre sus intereses actuales destaca la Historia de la Medicina, área en que mantiene una colaboración con el Dr. Ignacio Duarte, después de su retiro de la anestesia, y el estudio del lenguaje de la medicina y sus orígenes en el latín y el griego. En ambos campos tiene diversas publicaciones, que se añaden sin nada que escatimar, a aquéllas que hiciera en el campo de la anestesiología. También ha incursionado en la literatura, al publicar el cuento "Los Papiros de Kerameikos", que ganara un premio en la Sociedad Chilena de Historia de la Medicina.

Las actividades académicas del Dr. Dagnino, siempre ligadas ala Pontificia Universidad Católica de Chile, lo han llevado a alcanzar el Grado Académico de Profesor Titular, Encargado del Programa de Desarrollo Académico de Medicina Intensiva del Adulto, gestor del Curso de Bioestadística Básica y de Lectura Crítica, Director de Postgrado, gestor del Programa de Simulación en Medicina, Vicedecano de la Facultad de Medicina, Editor de la Revista Chilena de Anestesia y de la Revista Ars Medica, miembro del Comité Editorial del Journal of Anaesthesia History. En el año 2015 
fue nombrado Maestro de la Anestesiología Chilena por la Sociedad de Anestesiología de Chile y, recientemente, Profesor Emérito por la Pontificia Universidad Católica de Chile.

El discurso de ingreso del Dr. Dagnino a la Academia Chilena de Medicina, para el que utilizó metafóricamente el nombre de un famoso drama de Calderón de la Barca, lo vinculó inevitablemente al área de la anestesia y su experiencia personal en este quehacer, en lo que él denomina "tres elecciones o caminos impopulares", para referirse a las "encrucijadas" que debió enfrentar en su vida profesional: el primero, su decisión de postular a una beca de anestesiología, inicio de un largo y fascinante camino, y la descripción de algunos aspectos del desarrollo de la anestesiología a través de su historia en Estados Unidos e Inglaterra; el segundo, su dedicación a la bioestadística al darse cuenta de la gran cantidad de errores metodológicos existentes en prestigiosas revistas médicas y en estudios realizados por connotados investigadores, sin importar la especialidad o los países de origen; $y$, el tercero, el camino de las humanidades, de las lenguas muertas (griego y latín) y de la medicina muerta (historia de la medicina), incentivado por su relación y admiración con el Dr. Benedicto Chuaqui.

La conferencia del Dr. Dagnino es de gran interés para cualquier médico y de especial interés para los anestesiólogos. Su contenido completo se puede ver y escuchar en la página web de la Academia Chilena de Medicina: https://www.academiachilenademedicina.cl/2020/12/14/ceremonia-de-ingreso-del-drjorge-dagnino-sepulveda-como-miembro-honorario- de-la-academia-chilena-de-medicina/ Y también está disponible a través de YouTube en el sitio: https:// www.youtube.com/watch?v=zQkQtloNeZg\&feature =youtu.be

Como dijera el propio Dr. Dagnino en su conferencia, este es "de alguna manera un reconocimiento académico a la contribución médica y tecnológica de la anestesiología, una especialidad fascinante y desafiante, largamente ignorada por legos y versados". Sin embargo, es también un reconocimiento a la persona del Dr. Dagnino, su calidad humana, su capacidad docente, su enorme caudal de conocimientos en todas las áreas del saber y su inteligencia emocional. Es así como, para la comunidad anestésica, para la Sociedad de Anestesiología de Chile y para la Revista Chilena de Anestesia, es un gran honor compartir la noticia de su nombramiento como Miembro Honorario de la Academia Chilena de Medicina.

Es la oportunidad en esta ocasión de recordar y hacer un homenaje a otros eminentes anestesiólogos que perfectamente pudieron haber alcanzado el mismo honor y no fueron considerados, por ser la nuestra una especialidad hasta hace poco tiempo subvalorada: figuras destacadas en la historia de nuestra especialidad, como el Dr. Ernesto Frías Meneses, el Dr. Luis Cabrera Guárderas y el Dr. Jorge Urzúa Urzúa. Es probable que en los actuales tiempos, las señeras y activas contribuciones de estos insignes anestesiólogos a la medicina chilena, hubieran gozado del mismo reconocimiento.

Larga vida y muchas gracias al Dr. Jorge Dagnino Sepúlveda. 